\title{
HUBUNGAN PERAN PERAWAT SEBAGAI EDUKATOR DENGAN TINGKAT STRES HOSPITALISASI ANAK PRA SEKOLAH DI RUANG DELIMA RSUD.Dr HARDJONO PONOROGO
}

\author{
Putri Lestari \\ (PROGRAM STUDI S1 ILMU KEPERAWATAN, STIKES BUANA HUSADA PONOROGO) \\ Email: putrilesakper97@gmail.com
}

\begin{abstract}
Hospitalization is a condition in which children are treated in a hospital that will causes emotional feellings such as feelings of excensive stress and not being able to think well. Therefore the role of nurses is needed in reducing stress levels in children. The purpose of this research is to know the The relationship between the role of nurses and the stress level of hospitalization for pre-school children in the pomegranate room RSUD Dr. Harjono Ponorogo. Research design correlational study. Research population all patients in the pomegranate room RSUD Dr. Harjono Ponorogo. The Sample used in this study was pre-school children aged 3-6 respondent in the pomegranate room RSUD Dr. Harjono Ponorogo. Sampling technique is total sampling, the number of samples is 30 respondents. Independent variabel the role of the nurses, dependent variabel is stress level. Test statistical Spearman Rank test. Based on the results of the correlation between the role of nurses and the stress level of hospitalization for pre-school children using spearman rank correlation test shows $p$ value $=0,00$ value means $<$ significant value of 0,05 , with a correlation value of $-0,653$ or a negative correlation, $\mathrm{HO}$ is rejected meaning there is a relationship between the role of nurses and the stress level of hospitalization for pre-school children in the pomegranate room RSUD Dr. Harjono Ponorogo.
\end{abstract}

Keywords: Stress, Hospitalization, Nurse's Role

\section{PENDAHULUAN}

Pelayanan Kesehatan di Indonesia sangat beragam, salah satunya rumah sakit. Rumah Sakit merupakan sarana pelayanan Kesehatan masyarakat yang mempunyai peranan penting dalam meningkatkan derajat Kesehatan masyarakat.

Pelayanan yang terdapat di rumah sakit diantaranya, rawat jalan, rawat inap dan gawat darurat. Rawat inap terdiri dari ruang bedah, ruang operasi, ruang rontgen, ruang bersalin, dan ruang anak. Rumah sakit terdapat tenaga Kesehatan yang membantu dalam pelayanan Kesehatan salah satunya perawat (Permenkes, 2010).

Perawat merupakan seseorang yang mempunyai kemampuan dalam melaksanakan asuhan keperawatan kepada pasien sesuai dengan ilmu keperawatan. Peran Perawat merupakan tingkah laku yang diharapkan seseorang terhadap orang lain (Hidayat, 2008)

Stres Hospitalisasi merupakan respon individu terhadap situasi yang menimbulkan tekanan perubahan, tuntutan, penyesuaian diri. Stres Hospitalisasi akan menimbulkan perasaan tidak nyaman baik pada anak maupun keluarga, sehingga diperlukan penyesuaian diri untuk mengurangi stress (Hidayat, 2008).

Berdasarkan data WHO (World Health Organization) tahun 2010 bahwa $3 \%-10 \%$ pasien anak yang dirawat di Amerika Serikat mengalami stres selama hospitalisasi. Sekitar 3\%-7\% dari anak usia sekolah yang dirawat di Jerman juga mengalami hal yang serupa, 5\%-10\% 


\section{Jurnal Delima Harapan 2020}

anak yang di hospitalisasi di Kanada dan Selandia Baru juga mengalami stres selama dihospitalisasi.

Pada tahun 2013, jumlah anak yang ada dijawa timur sebanyak 2.485.218, dari jumlah tersebut 1.475 .197 sakit dan merasakan stress saat menjalani perawatan sebanyak $85 \%$ (Dinkes Provinsi Jawa Timur, 2014 dalam saputro, 2017).

Menurut data di ruang de;ima RSUD Dr. Harjono Ponorogo, berdasarkan wawancara dan observasi terhadap 10 anak pasien pra sekolah, 5 pasien mengalami stress.

Faktor yang mempengaruhi stress,perpisahan, kehilangan kendali, rasa sakit (Nursalam, 2005).

Upaya untuk meminimalkan respon stres terhadap hospitalisasi menurut Hockenberry dan Wilson (2007), dapat dilakukan hal-hal sebagai berikut: (1) mempertahankan aktivitas yang menunjang perkembangan, (2) bermain, (3) memaksimalkan manfaat hospitalisasi anak, (4) mendukung anggota keluarga, (5) mempersiapkan anak untuk dirawat di rumah sakit.

Tujuan dari penelitian ini untuk mengetahui hubungan peran perawat sebagai edukator dengan tingkat stres hospitalisasi anak pra sekolah di ruang delima RSUD Dr. Hardjono Ponorogo.

\section{METODE PENELITIAN}

Desain Penelitian yang digunakan dalam penelitian ini adalah kolerasional dengan pendekatan cross sectional. Penelitian dilaksanakan bulan Desember 2018-sampai dengan April 2019 di Ruang Delima RSUD Dr. Hardjono Ponorogo Jalan Raya Pacitan-Ponorogo, No. 80-83, Ponorogo. Populasi dalam penelitian ini adalah anak pra sekolah di ruang Delima, besar sampel 30 anak, yang digunakan dalam penelitian ini adalah pasien anak pra sekolah usia 3-6 tahun di ruang Delima, yang diambil berdasarkan teknik total sampling. Instrumen dalam penelitian ini adalah lembar kuesioner terdiri dari 2 item pertanyaan, pertama adalah sikap peran perawat sebanyak 12 pertanyaan, kedua adalah tingkat stres sebanyak 10 pertanyaan.

\section{HASIL dan PEMBAHASAN}

\section{A. Data Umum}

a. Karakteristik

responden

berdasarkan usia

Dari hasil penelitian di dapatkan hasil penelitian bahwa dari 30 responden yang diteliti, sebagian besar berusia 3 tahun sebanyak 14 pasien $(47 \%)$

b. Karakteristik responden berdasarkan jenis kelamin

Dari hasil penelitian di dapatkan hasil penelitian bahwa dari 30 responden yang diteliti, sebagian besar berjenis kelamin perempuan sebanyak 16 pasien (53\%).

c. Karakteristik orang tua pasien berdasarkan usia

Dari hasil penelitian di dapatkan hasil penelitian bahwa dari 30 responden orang tua pasien berusia 29-30 tahun sebanyak 8 orang $(27 \%)$.

d. Karakteristik orang tua pasien berdasarkan jenis kelamin

Dari hasil penelitian di dapatkan hasil penelitian bahwa dari 30 responden orang tua pasien, sebagian besar berjenis kelamin laki-laki sebanyak 16 pasien $(53 \%)$.

\section{B. Data Khusus}

a. Peran Perawat

Tabel 1. Peran Perawat sebagai edukator di ruang Delima RSUD Dr. Harjono Ponorogo

\begin{tabular}{ccc}
\hline $\begin{array}{c}\text { Peran } \\
\text { Perawat }\end{array}$ & Frekuensi & $\mathbf{( \% )}$ \\
\hline Kurang & 8 & $27 \%$ \\
\hline Cukup & 7 & $23 \%$ \\
\hline Baik & 15 & $50 \%$ \\
\hline Jumlah & $\mathbf{3 0}$ & $\mathbf{1 0 0 \%}$ \\
\hline \multicolumn{2}{c}{ Dari penelitian di } & dapatkan hasil \\
penelitian bahwa dari & 30 & responden \\
yang diteliti, sebanyak 15 responden \\
(50\%) peran perawat sebagai edukator \\
di ruang Delima RSUD Dr. Harjono \\
Ponorogo memilik kategori Baik.
\end{tabular}




\section{Jurnal Delima Harapan 2020}

b. Tingkat Stress

Tabel 2. Tingkat Stres Hospitalisasi anak pra sekolah di ruang Delima RSUD Dr. Harjono Ponorogo

\begin{tabular}{lcc}
\hline \multicolumn{1}{c}{$\begin{array}{c}\text { Tingkat } \\
\text { Stres }\end{array}$} & Frekuensi & $\mathbf{( \% )}$ \\
\hline Tidak Stres & 0 & $0 \%$ \\
\hline Stres Ringan & 12 & $40 \%$ \\
\hline $\begin{array}{l}\text { Stres } \\
\text { Sedang }\end{array}$ & 15 & $50 \%$ \\
\hline Stres Berat & 3 & $10 \%$ \\
\hline \multicolumn{1}{c}{ Jumlah } & $\mathbf{3 0}$ & $\mathbf{1 0 0 \%}$ \\
\hline Dari hasil & penelitian & didapatkan
\end{tabular}

hasil bahwa dari 30 responden yang diteliti, sebanyak 15 responden $(50 \%)$ mengalami stres sedang.

c. Tabulasi Silang Hubungan Peran Perawat sebagai Edukator dengan Tingkat Stres Hospitalisasi Anak Pra Sekolah di Ruang Delima RSUD Dr. Harjono Ponorogo.

Berdarkan hasil penelitian menunjukkan hasil bahwa analisa hubungan peran perawat sebagai edukator dengan tingkat stres hospitalisasi anak pra sekolah di ruang delima RSUD Dr. Harjono Ponorogo adalah peran perawat kurang stres sedang $(26,6 \%)$, peran perawat cukup stres ringan $(3,3 \%)$, peran perawat cukup stres sedang $(16,6 \%)$, peran perawat baik stres ringan $(33,3 \%)$, peran perawat baik stres sedang $(13,3 \%)$, peran perawat baik stres berat $(3,3 \%)$.

d. Hubungan Peran Perawat sebagai Edukator dengan Tingkat Stres Hospitalisasi Anak Pra Sekolah di Ruang Delima RSUD Dr. Harjono Ponorogo

Nilai $\mathrm{p}$ value $=0,00$ berarti < nilai signifikan 0,05 , maka dapat disimpulkan bahwa ada hubungan peran perawat sebagai edukator dengan tingkat stres hospitalisasi anak pra sekolah di Ruang Delima RSUD Dr. Harjono Ponorogo.
PEMBAHASAN

Peran Perawat sebagai edukator di Ruang Delima RSUD Dr. Harjono Ponorogo

Berdasarkan table 1.1 di dapatkan hasil penelitian bahwa dari 30 responden yang diteliti, peran perawat di ruang Delima RSUD Dr. Harjono Ponorogo memiliki pengetahuan baik 15 responden (50\%), pengetahuan kurang 8 responden $(26,7 \%)$. Data demografi responden menunjukkan bahwa responden terbanyak berusia 3 tahun sebanyak 14 responden (47\%) dan responden dengan jenis kelamin terbanyak perempuan sebanyak 16 responden $(53 \%)$

Peran Perawat suatu tingkah laku yang diharapkan orang lain terhadap seseorang sesuai dengan kedudukan dalam system, dimana dapat dipengaruhi oleh keadaan sosial baik dari profesi perawat maupun dari luar profesi keperawatan yang bersifat konstan (Hidayat, 2008).

Peran perawat yang baik dapat diartikan sebagai adanya kemampuan dalam memberikan educator kepada pasien. Kemampuan ini dapat dipengaruhi dengan memadainya karakter pribadi perawat (Bastabel, 2002 dalam Hapsari, 2003).

Peran Perawat yang baik dalam pemberi pelayanan kesehatan dipengaruhi oleh banyak faktor seperti, pengetahuan dan sikap mengambil bagian penting yang bisa mempengaruhi pelaksanaan peran perawat. Faktor lain yang mempengaruhi peran perawat adalah kondisi pasien, kebudayaan pasien, bahasa sehari-hari yang digunakan pasien, dan kemampuan pasien dan keluarga dalam menerima segala informasi yang diberikan oleh perawat.

Peran Perawat diruang delima baik karena di ruang delima perawat mampu memberikan edukator kepada pasien dalam menjalankan asuhan keperawatan di samping pemberi pelayanan kesehatan. Saat ini, peran perawat bagi pasien, keluarga pasien dan masyarakat umum semakin meningkat seiring dengan perkembangan teknologi. Selain itu, 
perawat juga dapat memfasilitasi untuk belajar, mendapat kunjungan dari teman.

\section{Tingkat stres hospitalisasi anak pra sekolah di ruang Delima RSUD Dr. Harjono Ponorogo}

Berdasarkan tabel 4.6 di dapatkan hasil penelitian bahwa dari 30 responden yang diteliti, sebagian besar responden mengalami stres sedang sebanyak 15 pasien (50\%) dan responden yang mengalami stres berat sebanyak 3 responden $(10 \%)$. Hal ini bisa disebabkan karena responden dalam penelitian ini mendapatkan informasi tentang penyakit yang dialami.

Reaksi anak terhadap sakit dan rawat inap di rumah sakit berbeda-beda pada masing-masing individu. Hal tersebut dipengaruhi oleh beberapa faktor. Perkembangan usia anak merupakan salah satu faktor utama yang dapat mempengaruhi reaksi anak terhadap sakit dan prosesn perawatan (Supartini, 2004).

Faktor yang mempengaruhi tingkat stres pada anak yaitu usia dan jenis kelamin. Sebagian besar yang mengalami stres yaitu usia 3 tahun sebanyak 14 pasien (47\%) dan sebagian besar anak dengan jenis kelamin perempuan sebanyak 16 pasien $(53 \%)$. Usia erat kaitannya dengan kematangan dan pengalaman seseorang dalam menghadapi permasalahan yang ada. Semakin cukup usia, tingkat kematangan dan kekuatan anak akan lebih matang dalam berfikir dan bertindak dalam menghadapi suatu kondisi (Notoadmojo, 2007). Pernyataan diatas menerangkan bahwa usia anak mempengaruhi anak dalam berfikir dan bertindak menanggapi perawatan yang diterima di rumah sakit.

Sedangkan jenis kelamin perempuan mempengaruhi stres karena adanya pengaruh hormon esterogen yang dapat membuat anak lebih mudah mengalami stres (Sunarni, 2017).

Berdasarkan teori Faktor-faktor yang menyebabkan stres hospitalisasi pada anak diantaranya: Lingkungan yang ada di rumah sakit, berpisah dengan keluarga, kurang informasi tentang penyakitnya, masalah pengobatan yang dijalani anak. (Wong, 2009).

Berdasarkan uraian diatas peneliti menyatakan bahwa pasien dan keluarga yang dibekali informasi mengenai penyakitnya akan lebih mematuhi rencana perawatan medis dan mendapatkan cara untuk mengatasi dan menangani gejala penyakitnya. Sehingga pasien yang dirawat bisa meminimalkan stres yang dialami dan menerima tindakan yang diberikan oleh perawat/tenaga kesehatan lainnya.

Selain pasien dan keluarga dibekali informasi penataan lingkungan yang bernuansa anak dapat meningkatkan keceriaan, perasaan aman, dan nyaman bagi lingkungan anak sehingga anak selalu berkembang dan merasa nyaman dilingkungan rumah sakit.

Bagi anak yang di hospitalisasi dalam jangka waktu yang panjang, perawat sebisa mungkin membuat ruangan senyaman mungkin dengan membuat dekorasi dinding gambar kartun atau bunga-bunga yang membuat ruangan itu serasa milik pribadi anak dan selama anak dirawat akan dihadapkan dengan suara bising seperti peralatan medis, maka perawat harus memberi penjelasan yang dapat membuatnya mengerti akan hal tersebut sehingga perasaan stres akan berkurang.

Hubungan peran perawat sebagai edukator dengan tingkat stres hospitalisasi anak pra sekolah di ruang Delima RSUD Dr. Harjono Ponorogo

Berdasarkan uji Spearman Rank yang menggunakan SPSS menunjukkan bahwa nilai $\mathrm{p}$ value $=0,00$ berarti $<$ nilai signifikan 0,05, maka dapat disimpulkan bahwa ada hubungan peran perawat sebagai edukator dengan tingkat stres hospitalisasi anak pra sekolah. Dari hasil Correlation Coefficient juga diperoleh nilai $-0,653$ atau korelasi yang negatif. Artinya semakin tinggi peran perawat maka semakin rendah tingkat stres. Berdasarkan hasil tersebut maka H0 ditolak yang artinya ada hubungan peran perawat dengan tingkat stres hospitalisasi anak pra sekolah. Dalam penelitian ini 
peran perawat sangat berpengaruh terhadap tingkat stres.

Menurut Burhanudin (2011) menyatakan bahwa peran perawat sebagai edukator sangatlah penting untuk mengendalikan stres pada pasien anak. Peran perawat sebagai peran edukator jika tidak dilakukan maka pasien akan merasakan stres, dan tidak adanya kemampuan menerima prosedur tindakan di rumah sakit. Adapun hal lain yang terjadi jika perawat tidak memberikan informasi kepada pasien maka pasien akan menjalani perawatan di rumah sakit lebih lama. Perawat diharapkan dapat memberikan edukasi dengan baik dan jelas agar tidak menambah tekanan stresor yang dapat membuat pasien stres selama di rawat di rumah sakit karena perawat memiliki peranan penting terhadap proses penyembuhan pasien.

Berdasarkan hasil penelitian yang peneliti dapatkan mengenai adanya peran perawat dengan stres hospitalisasi pada anak pra sekolah, maka peneliti berpendapat bahwa peran perawat dibutuhkan terhadap stres hospitalisasi, bentuk peran perawat seperti menjelaskan tentang penyakit yang dialaminya, menjelaskan prosedur tindakan dan pengobatan yang akan diberikan kepada anak, meningkatkan tingkat pengetahuan kesehatan dan kemampuan kepada anak, meyakinkan kepada anak untuk patuh dalam mengikuti perawatan di rumah sakit. Hal ini membuat anak merasa nyaman dan tidak stres menghadapi tindakan atau pengobatan dari tenaga medis.

\section{SIMPULAN}

a. Sebagian Besar peran perawat di Ruang Delima RSUD Dr. Harjono Ponorogo baik sebanyak 15 responden (50\%).

b. Sebagian besar anak pra sekolah di ruang Delima RSUD Dr. Harjono Ponorogo mengalami tingkat stres sedang sebanyak 15 responden (50\%).

c. Terdapat hubungan antara peran perawat dengan tingkat stres hospitalisasi anak pra sekolah di
Ruang Delima RSUD Dr. Harjono Ponorogo dengan nilai $\mathrm{p}$ value 0,00 $(<0,05)$ dan hasil Corelation Coefficient diperoleh nilai-0,653.

\section{SARAN}

a. Bagi Institusi Pendidikan

Hasil Penelitian ini diharapkan dapat menjadi tambahan wawasan di Institusi pendidikan khususnya di bidang keperawatan anak.

b. Bagi Ruang Delima RSUD Dr. Harjono Ponorogo

Dapat mempertimbangkan penelitian ini karena masih adanya responden yang mengalami stres sedang.

c. Bagi Perawat di Ruang Delima RSUD Dr. Hardjono Ponorogo

Perawat perlu meningkatkan perannya sebagai edukator kepada pasien dan keluarga mengigat pentingnya peran educator bagi pasien dan keluarga.

d. Bagi Keluarga

Diharapakan dapat terpacu untuk menggali informasi mengenai tindakan yang akan dijalani agar mengurangi tingkat stres.

\section{DAFTAR PUSTAKA}

Aziz Alimul Hidayat. 2008. Konsep Dasar Keperawatan. Edisi 1.Jakarta: Salemba Medika

Aziz Alimul Hidayat. 2008. Ilmu Kesehatan Anak. Edisi 2. Jakarta: Salemba Medika

Bastabel. 2002. Perawat sebagai pendidik: $\quad$ Prinsip-prinsip pengajaran dan pembelajaran. Jakarta: EGC

Hockenberg \& Wilson. 2007. Nursing Care Of Infants and Children. St. Loius: MoshyElsevies

Menkes RI. Peraturan Mentri Kesehatan Republik Indonesia Nomor 147/Menkes/Per/I/2010 tentang Perizinan Rumah Sakit. Jakarta : Kemenkes RI : 2010

Notoadmojo. 2007. Promosi Kesehatan dan ilmu perilaku. Jakarta : Rineka cipta 


\section{Jurnal Delima Harapan 2020}

Wong. 2009. Buku Ajar Keperawatan Pediatrik. Edisi 6. Jakarta: EGC

Raditya Wahyu Hapsari.2013.Hubungan Peran Perawat Sebagai Edukator Dengan Pemenuhan Kebutuhan Rasa Aman Pasien Di Ruang Rawat Inap Rumah Sakit Umum Dr. H. Koesnadi Kabupaten Bondowoso. Skripsi Program studi ilmu keperawatan Universitas Jember 